\title{
The Effect of School Space on Pedagogical Practices and Students' Learning Outcomes: A Review of Scientific Sociological Literature
}

\author{
Archontoula Lagiou, Anna Asimaki, Gerasimos Koustourakis \& Georgios Nikolaou \\ University of Patras, GREECE \\ School of Humanities and Social Sciences
}

Received: 28 April 2021 - Accepted: 29 June 2021 • Published Online: 9 August 2021

\begin{abstract}
School space is an important factor in the realization of educational work since it shapes the material conditions for the implementation of the educational process. The aim of this paper, which focuses on a review of contemporary sociological scientific literature, is to investigate and highlight the effect of school space on the shaping of pedagogical practices, as well as on the pupils' learning outcomes. Study and analysis of the content of research findings and relevant scientific papers reveal that school space is chiefly "mono-functional" and that both teachers and pupils remain caught up in the implementation of what are largely traditional pedagogical practices. School space clearly needs to be adapted to the new pupil-centered pedagogical methods, and this can only be achieved through the initiative and agency of the teachers. Finally, it is also clear that the pupils' learning outcomes are to a great extent linked to the position they occupy in the space within the school classroom.
\end{abstract}

Keywords: School space, pedagogical practices, learning outcomes.

\section{Introduction}

During the four last decades, the importance of school space in the shaping of the way educational work is carried out, has been highlighted (Christie, 2002; Wasnock, 2010). School space is defined as a versatile material reality and as an anthropogenic environment which reflects the humanitarian values and models of behavior of the society that produces it, and it actively, dynamically and experientially embodies the role of the school (Lim, O'Halloran \& Podlasov, 2012; Urwick \& Junaidu, 1991).

School space, where pupils of various ages with different interests, educational needs and characteristics come together every day, is a field for the provision of knowledge and education, the acquisition and cultivation of skills, for socialization and communication, gameplaying as well as the holding of events (Germanos, 2009; Gislason, 2007; Koustourakis, 2018b). In addition, the school environment is sometimes approached as an inanimate structure and not as a space created in the context of certain educational beliefs aimed at enveloping and supporting the pupils' learning processes and consequently the complex and multi-level work of the teachers (Berris \& Miller, 2011; Neill \& Etheridge, 2008).

(C) Authors. Terms and conditions of Creative Commons Attribution 4.0 International (CC BY 4.0) apply. Correspondence: Archontoula Lagiou, University of Patras, School of Humanities and Social Sciences, Patras, GREECE. E-mail: liyeosa@gmail.com. 
Study of the contemporary scientific literature reveals that school space is the fundamental field in which both the interaction between teachers and students, and the deployment of pedagogical practices are realized. Hence, the role played by school space is extremely important since it may influence either directly or indirectly the quality of the interpersonal relationships. The formation and suitability of the school space, with the essential material conditions which ensure the existence of a pleasant and creative learning environment are the goals for meeting the needs and demands of daily school activities (Alterator \& Deed, 2013; Berris \& Miller, 2011; Cheryan, Ziegler, Plaut \& Meltzoff, 2014; Christie, 2002; Figueroa, Lim \& Lee, 2016; Ghaziani, 2010; Gislason, 2009a; Kaya \& Burgess, 2007; Koustourakis, 2018c; Kuuskorpi \& Cabellos Gonzalez, 2011; Martin, 2002; McGregor, 2004; Perkins \& Wieman, 2005; Szteinberg \& Finch, 2006; Urwick \& Junaidu, 1991; Wasnock, 2010). With this in mind, criteria for the design of a contemporary school unit are both the actual needs of the subjects that will experience it and use it on a daily basis, and the interactive processes that are expected to govern the relationship that develops between them (Gislason, 2009b; Leiringer \& Cardellino, 2011; Marx, Fuhrer \& Harting, 1999). Consequently, the study, evaluation and improvement in the quality of the school space is one of the important parameters of the educational processes of everybody concerned with educational policy, programming, design and with the shaping of educational work (Douglas \& Gifford, 2001; Germanos, 2009).

The aim of this paper, which focuses on a review of contemporary scientific literature, is to investigate and highlight the influence of school space on the shaping of the teachers' pedagogical practices and the pupils' learning outcomes.

Following on from the section with the theoretical notes, the review of the scientific literature is classified into three specific units based on the thematic content of the relevant research studies. In the case of each thematic chapter there is a selective or brief presentation of the findings of certain representative papers, which shed light on the findings of the particular units. The paper closes with the concluding comments.

\section{Theoretical notes}

The approach to the issue under investigation is directly related to the utilization of Basil Bernstein's sociological theory. Code is a central concept in Bernstein's (1989, 1996) theoretical schema and is defined as a regulative principle which contains within its power relations and principles of social control. The code of educational knowledge refers to the fundamental principles that form the curriculum, the pedagogy, as well as the ways in which teachers evaluate pupils. These elements are the actualizations of the educational code (Bernstein, 1990). In addition, as a regulatory principle, the code is acquired silently by the subjects, shaping the forms for the implementation as well as the contexts for the expression, of their pedagogical practices. From this perspective, we can suppose that the code of the school space is an educational code which is decisive in defining, shaping and influencing the pedagogical practices implemented by the teachers at the micro-level of the school classroom.

Closely interwoven with the concept of code in Bernstein's theoretical framework, are the concepts of classification and framing (Asimaki, Lagiou, Koustourakis \& Sakkoulis, 2018; Bernstein, 1989, 1990; Koustourakis, 2018a). More specifically, classification depends on the power which determines what can be placed with what to form a category. What's more, it is linked to the realization of certain categories through the imposition of strong, or weak, borders and separations between these categories, such as school classrooms, for example (Bernstein, 1989; Hoadley, 2007). Framing refers to the "nature" and structure of the pedagogical relationship (teachers-pupils), as well as to the opportunity for the teacher and pupils to choose, organize, shape the time limits and pace the knowledge that is transmitted within each communicative framework (Bernstein, 1989: 68; Koustourakis, 2018a: 1212). In this case, we 
guess that the school spaces shaped for the realization and transmission of educational knowledge will be governed by strong classifications and framings and consequently will shape the pedagogical practices implemented by the teachers.

Closely linked to the concept of code, is the concept of pedagogical practices, which according to Bernstein $(1989,2000)$ are understood as the social framework through which cultural reproduction takes place. More specifically, two genetic types of pedagogical practice can be distinguished: the visible pedagogy, which places emphasis on strict procedures for the transmission and evaluation of knowledge, as well as on specialized forms of it. This kind of pedagogical practice is defined by strong classifications $(\mathrm{C}++/ \mathrm{C}+)$ and framings $(\mathrm{F}++/ \mathrm{F}+)$ of knowledge. In contrast, the invisible pedagogical practice is defined by weak classifications (C-/C-) and framings (F--/F-) and is oriented towards an autonomous course of learning for the acquisition of knowledge as well as towards more or less informal evaluation practices, based on a relaxed hierarchical relationship between teacher and pupils (Bernstein, 1989).

Bernstein (1989, 2000), assigns particular importance to the pedagogical relationship that develops between teachers and pupils, maintaining that its internal logic is based on three interconnected rules: (a) the hierarchical rules, which are necessary for shaping the appropriate behavior in each pedagogical relationship and which are linked to learning the roles of transmitter and receiver, which define rules of conduct, morals and social order, and (b) the rules of sequencing and pacing which concern the order in which school knowledge is transmitted, as well as the time frame for the pupils to acquire it (Bernstein, 1989: 115). Finally, through the acquisition and implementation of the criteria rules, the pupil understands which forms of communication, social relationship or position in the school field are permitted, and which not (Asimaki et al., 2018; Bernstein, 2000; Koustourakis, 2018a).

Bernstein $(1989,1990)$ proposes a model for the investigation of pedagogical practices that can reveal and interpret the interactions between teachers and pupils on the micro-level of the school classrooms that take place for the realization of the daily educational work. In the case of our research, the assumptions of the invisible pedagogical practice will be of great interest to us as these are analyzed and "illuminated" in relation to the space, as much on an economic level, as on a symbolic one. We suppose that the variables of space will determine the teachers' implemented pedagogical practices to a large extent, as well as the pupils' learning outcomes. In particular, the rules upon which the school space is built in the case of a visible pedagogy include implicit social and cognitive messages and strong explicit rules are implemented which determine the practices and the communications, applying the rule "leave the space as you found it" (Bernstein, 2000; Koustourakis, 2018b, 2018c). In contrast, in the case of an invisible pedagogical practice the rules that regulate the communications and the practices in the space are less restrictive and are characterized by the rule "make your mark" encouraging the individual action of each receiver (Bernstein, 1989, 2000).

\section{The structure, organization and modifications of the school space}

Recent scientific research has revealed that the structure and organization of school classrooms in many countries have remained unchanged for years. In other words, the regulative code of the school space seems to favor the implementation of mainly "visible" pedagogies that are linked to the implementation of strong classifications and framing (Bernstein, 1996, 2000). In particular, the features that characterize most of the contemporary school classrooms seem to bear a startling resemblance to older school classrooms (Berris \& Miller, 2011; Gislason, 2007; Szteinberg \& Finch, 2006; Urwick \& Junaidu, 1991; Wasnock, 2010). More specifically, it is noted that the organization of the space in school classrooms is based on the reproduction of the traditional features of older school buildings. A characteristic example of this is the arrangement of the desks, which cannot be easily altered, and as a result, even today they are arranged in parallel 
rows and columns facing the board and the teacher's desk. In addition, the position of the teacher's desk continues to be next to the board and the positions occupied by the pupils and teachers within the school classroom remain static, being constant and well-established (Germanos, 2009; Lim, O’Halloran \& Podlasov, 2012; Ghaziani, 2010; Gislason, 2009a; Kaya \& Burgess, 2007; Kuuskorpi \& Cabellos Gonzalez, 2011; Leiringer \& Cardellino, 2011; Martin, 2002; Marx, Fuhrer \& Hartig, 1999; McGregor, 2004).

From a study of the scientific works that focus on the structure and organization of the school space, it is noted that the classrooms at all levels of education (pre-school, primary, secondary, tertiary) seem to have remained unchanged, stagnant and mono-functional for many decades, despite the developments in contemporary pedagogical approaches. Consequently, there is a need for the immediate conversion and redesign of the school space to make possible the implementation of appropriate and contemporary teaching methods (Koustourakis, 2018b). In other words, interventions are necessary so that the environment in the school classrooms can become more flexible and approachable in order that quality learning actions can be developed (Abrentzen \& Evans, 1989; Douglas \& Gifford, 2001; Espey, 2008; Koustourakis, 2018c). From the content of studies that focus on the investigation of the attitudes of teachers and pupils concerning the space where the educational process is carried out, it emerges that they would like to see radical changes in the arrangement and organization of the spaces in their schools in order for them to be more functional. In particular, they would like to see changes in the furniture, the teaching aids in the classrooms, as well as changes in the internal decor. In addition, they would like to participate more in the design, arrangement and operation of their classrooms (Berris \& Miller, 2011; Douglas \& Gifford, 2001; Germanos, 2009; Ghaziani, 2010; Kuuskorpi \& Cabellos Gonzalez, 2011; Leiringer \& Cardellino, 2011; Neill \& Etheridge, 2008; Koustourakis, 2018b).

The findings of research by Berris and Miller (2011), which was carried out in kindergartens and primary schools in Australia, are characteristic. This research showed that the ideal way to shape school classrooms required two specific characteristics, which are: to be "familiar" to the pupils and the teachers, to be welcoming, to have appropriate lighting and ventilation, to be spacious and offer security to all those who use it. Teachers, pupils and parents emphasize the importance of the existence of the aforementioned features in the school classrooms so as to speed up the better development of the educational work for the pupils' benefit. In addition, the results of this research also revealed the need for the opportunity for greater flexibility, to be linked to the existence of windows for the provision of natural light and the circulation of cleaner air. Moreover, the need appeared for the existence in the classrooms of materials that could catch the pupils' interest, like mirrors and colorfully painted walls. A significant finding from the teachers' point of view was the need for the school classrooms to be spacious, so that they could implement alternative pedagogical practices and educational activities to better meet their pupils' needs. Finally, the teachers stressed the importance of linking the use of the internal with the external (outdoor) school space for the achievement of better learning outcomes (Berris \& Miller, 2011).

From the study of the scientific literature, it emerged that the code for the shaping of school space generally and the school classrooms in particular doesn't appear to correspond effectively to the development of educational processes and work that are based on contemporary needs. Consequently, the research findings that depict the views of the teachers and the pupils advocate the need for the "transformation" of the dominant code regarding the shaping of school space and the classrooms (Bernstein, 1989, 1996). 
4. The impact of school space on the pedagogical practices implemented by the teachers

School space, as a learning environment, can create the conditions so that the educational process may become more effective and pleasant. The impact of the structured school environment on the performance and conduct of teachers and pupils has been approached in research by scientists from various scientific fields, such as the pedagogical field, as well as sociologists, environmental psychologists and architects (Gislason, 2007; Martin, 2002). The findings from a lot of the research agree on the discovery that school space is an especially significant factor in the implementation of everyday educational activities and the shaping of the relationships that develop within the school environment. This is because a good quality school environment makes a significant contribution to the improvement in the quality of the educational work provided. In addition, it is ascertained that teachers are directly affected by the quality of their working environment, strengthening their ability to provide good quality educational work to their pupils. This in turn creates a positive attitude in the pupils and contributes to their active participation in the educational process and improves their pedagogical interactions with their teachers (Kuuskorpi \& Cabellos Gonzales, 2011; Martin, 2002; McGregor, 2004; Perkins \& Wieman, 2005; Szteinberg \& Finch, 2006).

However, the findings from contemporary studies reveal that school space is chiefly "mono-functional", in other words it always functions in a way that is linked to the implementation of traditional "visible" pedagogical practices (Bernstein, 1989, 2000; Bernstein, 2000; Koustourakis, 2018b). The formation of pedagogical relationships that correspond to the "monofunctional' nature of the space is also discerned in its one-dimensional character. In other words, it functions in one direction, which is from the teacher towards the pupils and not the other way around, which leads to stereotypical and inflexible pedagogical practices (Byers, Imms \& HartnellYoung, 2014; Gislason, 2007; Martin, 2002; Marx, Fuhrer \& Hartig, 1999). The 'model' for the organization of the school space influences the shaping of the teachers' pedagogical practices depending on the "openness" or the "closedness" of the orientation of the educational environment (Leiringer \& Cardellino, 2011). Consequently, the organization of the space and its dynamic make an important contribution to the appearance of different types of work in the school classroom and as a result, to the development of alternative forms of pedagogical practices (Alterator \& Deed, 2013; Wasnock, 2010).

The research by Szteinberg and Finch (2006), which took place in 2004 with secondary education teachers in five different cities in Poland, is characteristic. From the findings of this research, it was ascertained that most teachers saw the learning environment within which they worked as more focused on a teacher-centered approach, which is linked more to the implementation of a "visible" pedagogical practice (Bernstein, 2000). In this case the teaching actions were a "combination" of learning activities that moved mainly from the teacher and required the pupils to implement them, following his instructions and allowing the pupils themselves limited to no opportunity for autonomy. In addition, the results revealed that the teachers who based their teaching on a teacher-centered model, depended on and used more a traditional arrangement in the classroom, where the pupils' seats were strictly placed in rows and columns (Szteinberg \& Finch, 2006: 504-505). In contrast, teachers who adopted a pupil-centered approach, and moved towards the implementation of an "invisible" pedagogical practice (Bernstein, 1996, 2000), made more use of classrooms with a horse-shoe shape arrangement of desks. However, in both cases it was noted that the teachers didn't modify the organization and arrangement of their classrooms during the school year, since they didn't want to "upset" the communicative relationship that they had developed with their pupils (Szteinberg \& Finch, 2006: 502-506). Irrespective of the layout of the space and the arrangement of the pupils' seats that the teachers chose during the implementation of their teaching work (traditional, horse-shoe, circle or other), it appeared that they recognized the impact of other conditions that they could create in 
the school classrooms and which could contribute to the acquisition of knowledge. In particular, the teachers recognized the significance of group work and the pupils' active participation in the educational process. So, regardless of the pedagogical practices that they implemented based on the shaping of the space in their classrooms, it appeared that they recognized that a pupil-centered type of approach could be implemented, as long as they themselves had the knowledge and the willingness to modify and re-shape the traditional 'sterile' learning environment within which they worked (Szteinberg \& Finch, 2006: 5017-510).

The research studies recognize the importance of the teacher's ability to develop a creative relationship with the space, to use it as a pedagogical tool and to make use of it in the framework of his teaching. In this case, the teacher needs to have the ability to transform, rearrange and decorate the space, creating a learning environment that can encourage the creative movement of the pupils in the space in order to achieve positive learning outcomes. The way in which the teacher organizes the space reveals the framing choices he considers appropriate for the realization of his pedagogical work (Bernstein, 2000; Koustourakis, 2018b), and which are related to behaviors that are either permitted or not, favoring particular learning processes. In particular, from the study of the scientific literature it emerges that school space doesn't need to be approached as something immutable, or an obstacle, but can be approached as a "tool" that can support, enrich and modify the teachers' pedagogical practices (Betoret \& Artiga, 2004; Brooks, 2012; Byers, Imms \& Hartnell - Young, 2014; Gislason 2009b; Kristin \& Torfi, 2011; Marx, Fuhrer \& Hartig, 1999; Tanić, Nikolić, Stanković, Kondić, Živković, Mitković \& Keković, 2015; Wasnock, 2010).

Betoret \& Artiga's research (2004) which was carried out in the school year 2002 2003 with secondary education teachers, is representative of the previous observation. Its findings showed that most of the teachers that participated in it largely approved the implementation of an "invisible" pedagogical practice (Bernstein, 2000), linked chiefly to a pupil-centered model of teaching since they held idealistic and altruistic values regarding their pupils' education. However, they pointed out that the real 'world' of teaching, behind the closed door of the school classroom, is very different to the one they had originally imagined. The teachers who implemented the teacher-centered model of teaching, which gives precedence to the implementation of a "visible" pedagogical practice with explicit hierarchical rules, rules of sequencing and rules of criteria (Bernstein, 2000), worked in school classrooms in which there was a traditional front-facing arrangement of desks, which favored the teaching of specific contents of school knowledge (compulsory subjects, or subjects of choice) (Betoret \& Artiga, 2004). In addition, as far as the relationship between pedagogical practices and spatial layout within the school classroom is concerned, it appeared that the teachers who worked based on a teacher-centered method preferred a vertical or front-facing arrangement of desks. However, when the teachers implemented a pupil-centered approach they modified the space and used a semi-circular, group or Pi-shaped arrangement of desks. Consequently, the results of this research showed that the different preferences for the layout of desks in the school classrooms is closely connected to the teachers' choices regarding the manner of implementation of their educational work for the transmission of school knowledge (Betoret \& Artiga, 2005: 369-372).

\section{The impact of school space on the pupils' learning outcomes}

Classrooms with a "traditional" arrangement of seating that includes desks placed in rows, focus solely on the teacher and may increase the pupils' ability to concentrate as much on the lesson as on the other activities the teacher sets them to do (Figueroa, Lim \& Lee, 2016; Kaya \& Burgess, 2007; Perkins \& Wieman, 2005). In school classrooms where the desks are placed in rows and columns, lessons tend to be carried out that focus mainly on the teacher, which reveals the implementation of strict hierarchical rules of framing (Bernstein, 1996, 2000), as he is the 
main focal point in the room (Budge, 2000; Kalinowski \& Taper, 2007; Martin, 2002; Marx, Fuhrer \& Hartig, 1999). When learner-centered teaching approaches are chosen, then the lessons take place in school classrooms with a small number of pupils, and desks arranged in ways that permit teaching through group-work. In this case weak hierarchical rules of framing (Bernstein, 1996, 2000) are given precedence. In particular, in group type arrangements, two or four desks are placed together so that small groups of pupils can interact and work together. Groups are a common way of arranging desks where pupils work on a variety of learning projects and the teacher is able to work closely with them both individually and with the whole group (Benedict \& Hoag, 2004; Patton, Snell, Knight \& Gerken, 2001; Perkins \& Wieman, 2005).

A number of scientific studies that investigate the relationship between pupils choosing where to sit in the classroom and their learning outcomes have shown that children who choose to sit at the back of the classroom wish to be out of the teacher's line of sight and do not wish to participate in the learning procedure. In addition, in school classrooms where desks are arranged in rows and columns it was noted that the pupils sitting in the front rows participated more than the pupils who had chosen to sit at the back of the classroom (Gislason, 2009b; Holliman \& Anderson, 1986; Tagliacollo, Volpato \& Junior, 2010). It should be noted that the correlation between where the pupils sit in the classroom and school performance has hardly been studied at all.

At the beginning of the $20^{\text {th }}$ century Griffith (1921) published some of the first important research on this matter and noted that pupils who sit in the back row have a low academic performance. In other words, the connection between where the pupils sit and the implementation of criteria of framing is apparent (Bernstein, 1996, 2000). Later scientific studies showed that the pupils that sat near the board usually performed better at school, were absent less and participated more in class, paying greater attention during the teaching of each cognitive subject (Holliman \& Anderson, 1986; Pedersen, 1994; Benedict \& Hoag, 2004; Perkins \& Wieman, 2005). Perkins \& Wieman (2005) observed that pupils who sat at the back of the classroom participated less in the educational process and had a lower final grade. In addition, Kalinowski and Taper (2007) observed that the desks at the back of a classroom didn't appear to have a negative impact on the pupils' performance in the final exams. Most scientific studies reveal that where pupils sit affects their performance. Consequently, these findings lead teachers to the conclusion that if they change where the pupils sit, and move the pupils closer to the board and the front rows of desks then these pupils will perform better.

Research by Tagliacollo, Volpato and Junior (2010) which was carried out in primary schools in the city of Botucatu in Brazil studied whether where pupils sat in the classroom was correlated to their learning performance, as well as the factors that were likely to influence it. The research results revealed that the distance of the desks from the board correlated with the pupils' performance, as well as also being directly related with each pupil's total number of school absences. These relationships however are presented here as a result of a third component, which is the pupils' motivation for learning. The findings of this study showed that the pupils who sat in the front rows of desks received higher marks and were mostly present in class. In addition, it was discovered that pupils who sat in the front rows were more interested in learning and participation in the educational process. Moreover, it appeared that important reasons that influenced the choice of where to sit in class were friendship and social 'isolation' from the other pupils. Finally, significant too was the conclusion that pupils with motivation for more learning preferred to be close to the teacher, while those who were more occupied with the development of social relationships with their classmates remained at a distance from the teacher and were mainly found sitting at the back of the class (Tagliacollo, Volpato \& Junior, 2010: 200-201). 


\section{Concluding remarks}

Based on all of the above, we reach the following conclusions:

- From the analysis of the research findings, it emerges that the model of the school space in many countries in the western world is still characterized today as "stationary", favoring the development of visible pedagogical practices (Bernstein, 1996, 2000). In particular, the layout of the school building, the arrangement of a typical school classroom, and the relationship between inside and outdoor school space remain the same today, without any meaningful changes. The identical organization in school classrooms reveals a standardization of the spatial relations in the educational environment, which reinforces the teacher-centered character of the educational process (Ahrentzen \& Evans, 1989; Douglas \& Gifford, 2001; Espey, 2008). The quality of the educational process, the role of the "teacher/orator" and the "pupil/executor of instructions", the pupils' limited or non-existent opportunity to act autonomously and intervene in the educational process, to develop their critical skills and creativity, as well as the way in which the lesson is conducted, which resembles an unwritten 'educational ritual', are some of the important features of educational reality. Recent scientific data lead to the conclusion that school space is mainly "mono-functional", in other words it can function "in only one, and always the same, way". In addition, it was noted that teachers and pupils are "entrapped", in conditions for the arrangement of space and implementation of pedagogical practices that are a far cry from the framework determined by the educational and cultural dynamic of the school spatial environment. Consequently, initiatives for intervention and change in the conditions of the educational act appear to be essential, so as to activate a creative relationship between the members of the school community and the material space of the school classroom (Ghaziani, 2010; Gislason, 2009a; Kaya \& Burgess, 2007; Koustourakis, 2018b; Kuuskorpi \& Cabellos González, 2011; Leiringer \& Cardellino, 2011).

- School space needs to adapt to new pedagogical methods, which favor the implementation of "invisible" learner-centered pedagogical practices, in order to facilitate a new means of acquiring school knowledge (Bernstein, 1996, 2000). The front-facing arrangement of the desks needs to give way to a non-linear organization and large desks need to be abandoned and replaced with desks to be used in shapes appropriate for group work. The results of much research have shown that communication between teachers and pupils as well as the instructional - pedagogical practice for the transmission of knowledge remains largely teacher-centered. Regarding the relationship of communication to the form of desk arrangement in the school classroom, study results show that teachers' learner-centered behavior is expressed more in group and horse-shoe shaped desk arrangements than in the front-facing arrangement. In contrast, the teachers' teacher-centered practice seems to be associated more with the front-facing arrangement of desks, as opposed to a group-work arrangement (Kuuskorpi \& Cabellos González, 2011; McGregor, 2004; Perkins \& Wieman, 2005; Szteinberg \& Finch, 2006). However, an "ideal" space doesn't necessarily promote activities and pedagogical practices that originate in a contemporary pedagogy. The teacher has an important and decisive contribution to make to this relationship, and with the right knowledge and education he will contribute to the shaping of alternative and appropriate educational spaces. Recent research data reveal that for changes in teachers' pedagogical practices to come about, only one 'change' in the school space is not enough. An alternative spatial arrangement of the school classroom is pointless if not accompanied by corresponding changes in the pedagogical practices implemented by the teachers. Consequently, the role of the teacher in the pedagogical upgrading of the classroom and the use of space as a pedagogical tool, is decisive (Byers, Imms \& Hartnesll-Young, 2014; Gislason, 2007; Koustourakis, 2018b; Marx, Fuhrer \& Hartig, 1999).

- An important factor that is directly related to the improvement in pupil achievement is the arrangement of the school classroom, as well as where they sit. A number of 
scientific studies have highlighted the fact that the pupils who sit at the front of the class tend to be more active and achieve better results in meeting learning goals (Benedict \& Hoag, 2004; Patton, Snell, Knight \& Gerken, 2001; Perkins \& Wieman, 2005). These pupils appear to have a better interaction with the teachers in comparison with their classmates who sit at the back of the class and are 'hidden' from the teacher. Consequently, it is noted that in a school classroom, where the pupils sit is crucial as it determines their access to learning resources and opportunities for greater interaction with the teachers. The related literature reveals that pupils who sit near the board perform better at school in comparison with those who sit further away from it (Gislason, 2009b; Holliman \& Anderson, 1986; Tagliacollo, Volpato \& Junior, 2010). In addition, it is noted that the teachers' space of action is chiefly close to the board and their desk, and so it appears that teachers tend to address more questions to the pupils sitting at the front of the class. Moreover, in a number of cases, it is noted that the pupils who sit at the back of the class interact more with each other, talking and creating noise, something that disrupts the smooth conduct of the educational process and reduces their opportunities for learning and for achieving the expected learning outcomes (Benedict \& Hoag, 2004; Perkins \& Wieman, 2005).

To conclude this paper, we believe that a long-term bibliographical review of the scientific papers concerning the pedagogical redesign of the school space taking into account criteria regarding the organization and the instructional and psycho-social aspects of its operation would be of interest to the scientific community.

\section{Acknowledgements}

This research did not receive any specific grant from funding agencies in the public commercial, or not-for-profit sectors.

The authors declare no competing interests.

\section{References}

Ahrentzen, S., \& Evans, G. (1984). Distraction, privacy, and classroom design. Environment and Behavior, 16(4), 437-454. https://doi.org/10.1177/0013916584164002

Alterator, S., \& Deed, C. (2013). Teacher adaptation to open learning spaces. Issues in Educational Research, 23(3), 315-330.

Asimaki, A., Lagiou, A., Koustourakis, G., \& Sakkoulis, D. (2018). Training adequacy and pedagogic practices of teachers in reception facilities for refugee education in Greece during the economic crisis: A case study. Journal of Studies in Education, 8(3), 79-97. https://doi.org/10.5296/jse.v8i3.13396

Benedict, M. E., \& Hoag, J. (2004). Seating location in large lectures: Are seating preferences or location related to course performance? Journal of Economic Education, 35, 215-231. https://doi.org/10.3200/JECE.35.3.215-231

Bernstein, B. (2000). Pedagogy, symbolic control and identity. Theory, research, critique, Revised Edition. Lanham, Boulder, New York, Oxford: Rowman and Littlefield Publishers Inc.

Bernstein, B. (1996). Pedagogy, symbolic control and identity. Theory, research, critique. London: Taylor \& Francis Ltd.

Bernstein, B. (1990). The structuring of pedagogic discourse: Vol. IV Class, codes \& control. London: Routledge. 
A. Lagiou et al. - The Effect of School Space on Pedagogical Practices...

Bernstein, B. (1989). Pedagogical codes and control. Athens: Alexandreia.

Berris, R., \& Miller, E. (2011). How design of the physical environment impacts early learning: educators' and parents' perspectives. Australasian Journal of Early Childhood, 36(4), 1-17. https://eprints.qut.edu.au/46928/2/46928.pdf.

Betoret, F., \& Artiga, A. (2004). Trainee teachers' conceptions of teaching and learning, classroom layout and exam design. Educational Studies, 3o(4), 357-372.

https://doi.org/10.1080/0305569042000310309

Brooks, C. (2012). Space and consequences: The impact of different formal learning spaces on instructor and student behavior. Journal of Learning Spaces, 1(2), 1-10.

Budge, D. (2000). Secret is in the seating. Times Educational Supplement, No. 4396, 26-27.

Byers, T., Imms, W., \& Hartnell-Young, E. (2014). Making the case for space: The effect of learning spaces on teaching and learning. Curriculum and Teaching, 29(1), 5-19. https://doi.org/10.7459/ct/29.1.02

Cheryan, S., Ziegler, S., Plaut, V., \& Meltzoff, A. (2014). Designing classrooms to maximize student achievement. Policy Insights from the Behavioral and Brain Sciences, 1(1), 4-12. https://doi.org/10.1177/2372732214548677

Christie, F. (2002). Classroom discourse analysis. A functional perspective. London: Continuum.

Douglas, D., \& Gifford, R. (2001). Evaluation of the physical classroom by students and professors: a lens model approach. Educational Research, 43(3), 295-309. https://doi.org/10.1080/00131880110081053

Espey, M. (2008). Does space matter? Classroom design and team-based learning. Review of Agricultural Economics, 3O(4), 764-775. https://doi.org/10.1111/j.1467-9353.2008.00445.x

Figueroa, L., Lim, S., \& Lee, J. (2016). Investigating the relationship between school facilities and academic achievements through geographically weighted regression. Annals of GIS, 22(4), 273-285. https://doi.org/10.1080/19475683.2016.1231717

Germanos, D. (2009). Le réaménagement éducatif de l'espace scolaire, moyen de transition de la classe traditionnelle vers une classe coopérative et multiculturelle. Synergies Sud-Est Européen, 2, 85-101. http://gerflint.fr/Base/SE europeen2/germanos.pdf.

Ghaziani, R. (2010). School design: Researching children's views. Childhoods Today, 4(1), 1-30.

Gislason, N. (2007). Placing education: The school as architectural space. Paideusis, 16(3), 5-14. https://journals.sfu.ca/pie/index.php/pie/article/view/87/82.

Gislason, N. (2009a). Mapping school design: A qualitative study of the relations among facilities design, curriculum delivery, and school climate. The Journal of Environmental Education, 4O(4), 1734. https://doi.org/10.3200/joee.40.4.17-34

Gislason, N. (2009b). Building paradigms: Major transformations in school architecture (1798-2009). The Alberta Journal of Educational Research, 55(2), 230-248.

Griffith, C.R. (1921). A comment upon the psychology of audience. Psychological Monographs, 3o(3), 3647. https://psycnet.apa.org/doi/10.1037/hoo93148.

Hoadley, U. (2007). The reproduction of social class inequalities through mathematics pedagogies in South African primary schools. Journal of Curriculum Studies, 39(6), 679-706. https://doi.org/10.1080/00220270701261169

Holliman, W., \& Anderson, H. (1986). Proximity and student density as ecological variables in a college classroom. Teaching of Psychology, 13(4), 200-203. https://doi.org/10.1207/s15328023top1304_7

Kalinowski, S., \& Taper, M. L. (2007). The effect of seat location on exam grades and student perceptions in an introductory biology class. Journal of College Science Teaching, 36, 54-57. 
Kaya, N., \& Burgess, B. (2007). Territoriality. Environment and Behavior, 39(6), 859-876. https://doi.org/10.1177/0013916506298798

Koustourakis, G. (2018a). Analysing the curriculum for students with mild and moderate learning difficulties concerning the teaching of pre-vocational skills. British Journal of Sociology of Education, 39(8), 1210-1225. https://doi.org/10.1080/01425692.2018.1497948

Koustourakis, G. (2018b). Classroom space and kindergarten curriculum: a sociological approach to teachers' discourse on the status of space and its use in teaching. European Journal of Alternative Education Studies, 3(2), 47-65. https://doi.org/10.5281/zenodo.1422864

Koustourakis, G. (2018c). A sociological approach to the determination and implementation of rules for the pedagogical use of kindergarten classroom space. American International Journal of Social Science, $7(4), 20-28$. https://www.aijssnet.com/journals/Vol_7_No_4_December_2018/3.pdf.

Kristín, A., \& Torfi, H. (2011). School buildings for the $21^{\text {st }}$ Century - Some features of new school buildings in Iceland. Center for Educational Policy Studies Journal, 1(2), 25-43. https://files.eric.ed.gov/fulltext/EJ1130811.pdf.

Kuuskorpi, M., \& Cabellos González, N. (2011). The future of the physical learning environment. CELE Exchange, Centre for Effective Learning Environments, 2011/11, OECD Publishing, Paris. https://doi.org/10.1787/5kgolkz2dgf2-en

Leiringer, R., \& Cardellino, P. (2011). Schools for the twenty-first century: School design and educational transformation. British Educational Research Journal, 37(6), 915-934. https://doi.org/10.1080/01411926.2010.508512

Lim, F., O'Halloran, K., \& Podlasov, A. (2012). Spatial pedagogy: mapping meanings in the use of classroom space. Cambridge Journal of Education, 42(2), 235-251. http://doi.org/10.1080/0305764X.2012.676629

Martin, S. (2002). The classroom environment and its effects on the practice of teachers. Journal of Environmental Psychology, 22(1-2), 139-156. https://doi.org/10.1006/jevp.2001.0239

Marx, A., Fuhrer, U., \& Hartig, T. (1999). Effects of classroom seating arrangements on children's question-asking. Learning Environments Research, 2(3), 249-263. https://doi.org/10.1023/a:1009901922191

McGregor, J. (2004). Space, power and the classroom. FORUM, 46(1), 13-18.

Mills, C. (2003). Contesting the political: Butler and Foucault on power and resistance. Journal of Political Philosophy, 11(3), 253-272. https://doi.org/10.1111/1467-9760.00177

Neill, S., \& Etheridge, R. (2008). Flexible learning spaces: The integration of pedagogy, physical design, and instructional technology. Marketing Education Review, 18(1), 47-53. https://doi.org/10.1080/10528008.2008.11489024

Patton, J. E., Snell, J., Knight, W. J., \& Gerken, K. (2001). A survey study of elementary classroom seating designs. Annual Meeting of the National Association of School Psychologists, Washington, DC.

Pedersen, D. (1994). Privacy preferences and classroom seat location. Social Behavior and Personality: An International Journal, 22(4), 393-398. https://doi.org/10.2224/sbp.1994.22.4.393

Perkins, K., \& Wieman, C. (2005). The surprising impact of seat location on student performance. The Physics Teacher, 43(1), 30-33. https://doi.org/10.1119/1.1845987

Sztejnberg, A., \& Finch, E. (2006). Adaptive use patterns of secondary school classroom environments. Facilities, 24(13/14), 490-509. https://doi.org/10.1108/02632770610705275

Tagliacollo, V., Volpato, G., \& Junior, A. (2010). Association of student position in classroom and school performance. Educational Research, 1(6), 198-201. 
A. Lagiou et al. - The Effect of School Space on Pedagogical Practices...

Tanić, M., Nikolić, V., Stanković, D., Kondić, S., Živković, M., Mitković, P., \& Keković, A. (2015). Interconnection between physical environment and pedagogical process in elementary schools in Niš, Serbia. Current Science, 108(7), 1228-1234.

Urwick, J., \& Junaidu, S. (1991). The effects of school physical facilities on the processes of education: A qualitative study of Nigerian primary schools. International Journal of Educational Development, 11(1), 19-29. https://doi.org/10.1016/0738-0593(91)90006-t

Wasnock, D. (2010). Classroom environment: Emphasis on seating arrangement (Master Thesis). St. John Fisher College.

https://fisherpub.sjfc.edu/mathcs etd masters/17. 